\title{
Combined Influences of Gm and HLA Phenotypes upon Multiple Sclerosis Susceptibility and Severity
}

\author{
Jean-P. Salier, Richard Sesboüé, Claude Martin-Mondière," Maryvonne Daveau,‡ Pierre Cesaro," Brigitte Cavelier,\$ \\ Antoine Coquerel, $\|$ Liliane Legrand, I Jean M. Goust, ** and Jean D. Degos* \\ Institut National de la Santé et de la Recherche Médicale U-295, F-76800 Saint Etienne du Rouvray; ${ }^{*}$ Département de Neurologie, \\ Hôpital Henri Mondor, F-94010 Créteil; ¥Institut National de la Santé et de la Recherche Médicale U-78, F-76230 Bois-Guillaume; \\ $\S$ Centre Régional de Transfusion Sanguine, F-76230 Bois-Guillaume; \|Centre Hospitalier Régional, F-76000 Rouen; \Institut National \\ de la Santé et de la Recherche Médicale U-93, Hôpital Saint-Louis, F-75010 Paris, France; and **Departments of Neurology; and Basic \\ and Clinical Immunology and Microbiology, Medical University of South Carolina, Charleston, South Carolina 29425
}

\begin{abstract}
In some Caucasian populations, multiple sclerosis (MS) susceptibility has been independently related to given alleles of $H L A$ or $\mathbf{G m}$ systems that respectively code for major histocompatibility complex class I and II antigens or immunoglobulin $G$ heavy chains. Whether given combinations of alleles at both series of loci simultaneously influence MS susceptibility and/or severity was investigated by comparing 147 French MS patients and 226 geographically-matched healthy controls. The G2m(-23)/HLAB35 phenotype and G1m(-1)/HLA-B7(-)/HLA-DR2 phenotype were respectively associated with significant protection against (relative risk $=0.05$ ) and susceptibility to (relative risk = 4.3) MS. When considering MS severity, the presence of HLAB7 antigen correlated with a more severe disease in $G m^{1} / G m^{3}$ heterozygous patients, but not in $\mathrm{Gm}^{3} / \mathrm{Gm}^{3}$ homozygous patients. Conversely, an HLA-B12-associated milder disease was restricted to $\mathrm{Gm}^{3} / \mathrm{Gm}^{3}$ homozygotes. These results demonstrate the combined influence on MS of genetic loci that are unlinked but immune response-associated. Combined Gm and HLA typing is very likely able to serve as a prognostic indicator in this disease.
\end{abstract}

\section{Introduction}

The central nervous system demyelination that characterizes multiple sclerosis (MS) ${ }^{1}$ results, in most affected subjects, in a progressive disability that may fluctuate, but that will, in most cases, steadily increase over several decades. The pace of this progression, which is responsible for the severity of the disease, remains unpredictable.

MS aetiology is unknown, but the importance of genetic factors is well established (1). The major histocompatibility complex (MHC) loci on chromosome 6 code for HLA-A and -B (class I) and HLA-DR (class II) antigens. In northern Caucasians, an increased MS susceptibility relates to the presence

Address correspondence to Dr. Salier, Institut National de la Santé et de la Recherche Médicale U-295, BP 97, F-76800 Saint Etienne du Rouvray, France.

Received for publication 26 February 1986.

1. Abbreviations used in this paper: MHC, major histocompatibility complex; MS, multiple sclerosis; $R R$, relative risk.

J. Clin. Invest.

(C) The American Society for Clinical Investigation, Inc.

0021-9738/86/08/0533/06 \$1.00

Volume 78, August 1986, 533-538 of $H L A-A 3,-B 7$, or $-D R 2$ allele(s) (2-4), with the strongest association involving $H L A-D R 2(5)$, as recently reviewed $(1,6,7)$. In contrast to this well established HLA-related susceptibility, the importance of $H L A-B 7$ or $-D R 2$ in MS severity remains controversial $(5,7,8)$. It has also been suggested that, in the same ethnic group, susceptibility to MS is associated with the presence of certain combinations of alleles (haplotypes) at another series of immune response loci that code for the heavy chains of immunoglobulin G1 to G4 subclasses, i.e., the socalled $\mathrm{Glm}$ to $\mathrm{G} 4 \mathrm{~m}$ loci on chromosome 14 . Specifically, the $G m^{1 ; 21}$ haplotype is overrepresented in MS (9-11). Finally, MS susceptibility may be under the simultaneous influence of at least two unlinked genetic systems (12). The present study strongly suggests that the association of given Gm and HLA phenotypes influences the relative risk (RR) of expressing MS and the pace of its progression.

\section{Methods}

This study included 147 unrelated patients (53 males and 94 females) with a diagnosis of clinically definite MS according to classical criteria (13). Regardless of date of diagnosis, disease duration, relapse or remission, and evolution, all possible cases were included over a period of $5 \mathrm{yr}$ (1979-1983), provided that a blood sample could be obtained (after informed consent) for purposes of HLA and Gm typings. Control healthy population was made of 226 unrelated blood donors (132 males and 94 females). Both patient and control populations were quite similar with respect to ethnic origin (French Caucasian) and living area (Northwestern France) as previously detailed (14). Indeed, some subjects were excluded because: $(a)$ they were Caucasians but had a known non-French origin (four patients, one control), or (b) they displayed a non-Caucasian or rare $\mathrm{Gm}$ phenotype (five patients, three controls). The numbers of patients and controls quoted above corresponded to final figures after these eliminations.

Clinical evaluation of MS severity was estimated with a severity index, $K / D$, where $K$ is the degree of permanent disability on a scale graded from 1 to 10 according to Kurtzke (15), and $D$ represents the duration of disease expressed in years, with MS onset corresponding to the earliest defined neurological abnormalities known in each patient. Such data were available from the records of 141 patients with variable disease duration (mean $=8.7 \mathrm{yr}$, and 95\% range $=1.8-40.8 \mathrm{yr}$, after log transformation of the data). As estimation of disease severity is often inaccurate in patients with recent MS, the relevant comparisons were made among subjects having a minimum disease duration of $5 \operatorname{yr}(D \geqslant 5)$, a figure including $80 \%$ of the patients $(n=118)$. The latter group did not exhibit special over- or underrepresentation corresponding to the given $K$ or $D$ values whose distributions are detailed in Table $I$.

All patients and controls were typed by hemagglutination inhibition (16) for the six serologically detectable $\operatorname{Glm}(1,2,3), \operatorname{G} 3 \mathrm{~m}(11,21)$, and $\mathrm{G} 2 \mathrm{~m}(23)$ allotypes that are products of the corresponding $\mathrm{Gm}^{1}$ to $\mathrm{Gm}^{23}$ alleles of the $G 1 m, G 3 m$, and $G 2 m$ loci, respectively (G4m allotypes 
Table I. Disability Status Scale, Disease Duration, and Severity Index in 118 MS Patients with an MS Duration of at Least $5 \mathrm{yr}$

\begin{tabular}{llll}
\hline $\begin{array}{l}\text { No. of } \\
\text { patients }\end{array}$ & $\begin{array}{l}K^{*} \\
\text { mean and } \\
\text { (observed range) }\end{array}$ & $\begin{array}{l}D \ddagger \\
\text { mean§ and } \\
\text { (observed range) }\end{array}$ & $\begin{array}{l}K / D \\
\text { mean§ and } \\
\text { (observed range) }\end{array}$ \\
\hline 50 & 1.8 & 8.6 & 0.20 \\
& $(0-3)$ & $(5-27)$ & $(0-0.60)$ \\
51 & 5.2 & 12.9 & 0.39 \\
& $(4-6)$ & $(5-44)$ & $(0.12-1.20)$ \\
17 & 7.6 & 14.2 & 0.53 \\
& $(7-9)$ & $(5-29)$ & $(0.24-1.40)$ \\
118 & 4.1 & 11.1 & 0.31 \\
& $(0-9)$ & $(5-44)$ & $(0-1.40)$ \\
\hline
\end{tabular}

* Disability status scale, according to Kurtzke (15). For the sake of clarity, three arbitrarily $K$-defined classes are provided in this table; they were not used in subsequent analyses of disease severity (see Methods).

¥ Disease duration (years) calculated from MS onset to the time of $K$ determination.

$\S$ Mean calculated after log transformation of the data.

cannot be currently typed). The most probable $G m$ genotype was inferred from the $\mathrm{Gm}$ phenotype according to the known array of $\mathrm{Gm}$ haplotypes in Caucasians, namely $G m^{1,-2 ; 21}, G m^{1,2 ; 21}, G m^{3 ;-23 ; 11}$, and $G m^{3 ; 23 ; 11}$ (17). For all analyses, each individual was classified within either of two subpopulations with a $\mathrm{Gm}(+)$ or $(-)$ phenotype when considering each $\operatorname{Gm}(1,2,3$ or 23$)$ allotype alone (the above mentioned $G m$ haplotypes make the G3m allotypes useless for this purpose). When required, classifications were refined by splitting individuals according to the $G m$ haplotypes that delineate three major genotyped subpopulations, namely $G m^{1} / G m^{1}, G m^{1} / G m^{3}$, and $G m^{3} / G m^{3}$.

HLA typing was made from a heparinized blood sample. HLA-A and $-B$ antigens were tested in all patients and controls by the micro- cytotoxicity technique (18). HLA-DR specificities were determined on B lymphocytes using a standard technique (19); only $75 \%$ of the patients $(n=110)$ and $59 \%$ of the controls $(n=134)$ were DR-typed; it was checked within both populations that Gm, HLA-A, and -B antigens were similarly distributed between DR-typed and -untyped subjects. As HLA typings were obtained over several years and part of the individuals were not retyped for some recently defined antigens, the nomenclature used in our analyses corresponded to the original broad specificities (20). For all analyses, both patient and control populations were first divided according to the presence $(+)$ or absence $(-)$ of a given HLA antigen. When a given antigen $(a)$ displayed an uneven distribution and $(b)$ belonged to a well known haplotype, the classification was further extended to all possible combinations of one, two, or three of the haplotype-associated specificities, but restricted to their presence or absence, since $H L A$ genotypes were unknown in many individuals. Such an extended analysis was eventually performed on three haplotypes: $A 1, B 8, D R 3$; $A 3, B 7, D R 2$; and $A 2, B 12, D R 7$.

Computer-aided classification of all patients and controls was performed according to their $G m$ allotypes and/or genotypes, HLA specificities, sex, and disease severity. Statistical analyses were performed as in (21) with $(a)$ the chi-square test, the resulting probability being corrected for the number of nonindependent comparisons made when applicable and $(b)$ RR estimation according to Woolf's method with Haldane's correction, if necessary. Among patients, disease severity was studied by comparison of individual $K / D$ values with the nonparametric Mann-Whitney U test.

\section{Results}

In terms of the $\mathrm{Gm}$ system alone, none of the $\mathrm{Gm}$ phenotypes inferred an increased risk for MS, as already detailed (14). 16 HLA-A, 20 HLA-B, and 7 HLA-DR specificities were found within both populations. Antigen frequencies in controls (not shown) were similar to published values for Caucasians living in the same area (22). As usually found, MS patients displayed an HLA-DR2 prevalence $(P=0.009, \mathrm{RR}=2.03)$ which was restricted to HLA-B7 $(-)$ patients $(P=0.0005, R R=3.44)$ as shown in the right part of Table II.

Table II. Distributions of G1m(1), HLA-B7, and-DR2 Specificities in MS and Control Populations, and RR for MS

\begin{tabular}{|c|c|c|c|c|c|c|c|c|}
\hline \multirow[b]{2}{*}{$\begin{array}{l}\text { HLA-DR2 } \\
\text { G1m(1) }\end{array}$} & \multirow[b]{2}{*}{+} & \multirow[b]{2}{*}{$\begin{array}{l}+ \\
-\end{array}$} & \multirow[b]{2}{*}{+} & \multirow[b]{2}{*}{ - } & \multirow[b]{2}{*}{$\begin{array}{l}\text { Total } \\
\text { No. }\end{array}$} & \multicolumn{2}{|c|}{$\begin{array}{l}\text { HLA-DR2 } \\
\text { alone* }\end{array}$} & \\
\hline & & & & & & + & - & \\
\hline MS patients & 14 & 33 & 32 & 31 & 110 & 47 & 63 & \\
\hline Controls & 17 & 19 & 47 & 51 & 134 & 36 & 98 & \\
\hline RR‡ & $\begin{array}{l}1.00 \\
(0.47-2.14)\end{array}$ & $\begin{array}{l}2.59 \\
(1.38-4.89)\end{array}$ & $\begin{array}{l}0.76 \\
(0.44-1.31)\end{array}$ & $\begin{array}{l}0.64 \\
(0.42-0.97)\end{array}$ & & $\begin{array}{l}2.03 \\
(1.1\end{array}$ & & \\
\hline MS patients & 3 & 13 & 2 & 7 & 25 & 16 & $9^{\circ}$ & \\
\hline Controls & 9 & 12 & 2 & 6 & 29 & 21 & 8 & HLA-B7(+) \\
\hline $\mathbf{R R}$ & $\begin{array}{l}0.33 \\
(0.09-1.23)\end{array}$ & $\begin{array}{l}1.53 \\
(0.52-4.51)\end{array}$ & $\begin{array}{l}1.17 \\
(0.21-6.35)\end{array}$ & $\begin{array}{l}1.49 \\
(0.43-5.22)\end{array}$ & & $\begin{array}{l}0.68 \\
(0.2\end{array}$ & & \\
\hline MS patients & 11 & 20 & 30 & 24 & 85 & 31 & 54 & \\
\hline Controls & 8 & 7 & 45 & 45 & 105 & 15 & 90 & HLA-B7(-) \\
\hline $\mathbf{R R}$ & $\begin{array}{l}1.80 \\
(0.69-4.70)\end{array}$ & $\begin{array}{l}4.31 \\
(1.72-4.31)\end{array}$ & $\begin{array}{l}0.73 \\
(0.40-1.31)\end{array}$ & $\begin{array}{l}0.52 \\
(0.27-1.02)\end{array}$ & & $\begin{array}{l}3.4 \\
(1.7\end{array}$ & & \\
\hline
\end{tabular}

* HLA-DR2 (+) vs. (-) individuals, regardless of Gm allotypes. $¥ R R$, relative risk, and $95 \%$ confidence interval. 
Table III. Distributions of G2m(23) and HLA-B35 Specificities in MS and Control Populations, and RR for MS

\begin{tabular}{|c|c|c|c|c|c|c|c|}
\hline \multirow[b]{2}{*}{$\begin{array}{l}\text { HLA-B35 } \\
\text { G2m(23) }\end{array}$} & \multirow[b]{2}{*}{$\begin{array}{l}+ \\
+\end{array}$} & \multirow[b]{2}{*}{$\begin{array}{l}+ \\
-\end{array}$} & \multirow[b]{2}{*}{$\overline{+}$} & \multirow[b]{2}{*}{-} & \multirow[b]{2}{*}{$\begin{array}{l}\text { Total } \\
\text { No. }\end{array}$} & \multicolumn{2}{|c|}{ HLA-B35 alone* } \\
\hline & & & & & & + & - \\
\hline MS patients & 17 & 0 & 102 & 28 & 147 & 17 & 130 \\
\hline Controls & 24 & 14 & 140 & 48 & 226 & 38 & 198 \\
\hline $\mathbf{R R} \ddagger$ & $\begin{array}{l}1.10 \\
(0.57-2.13)\end{array}$ & $\begin{array}{l}0.05 \\
(0.01-0.38)\end{array}$ & $\begin{array}{c}1.39 \\
(0.89-2.17)\end{array}$ & $\begin{array}{l}0.87 \\
(0.52-1.47)\end{array}$ & & $\begin{array}{l}0.65 \\
(0.35-1.20)\end{array}$ & \\
\hline
\end{tabular}

* HLA-B35(+) vs. (-) individuals, regardless of Gm allotypes. $\ddagger R R$, relative risk and $95 \%$ confidence interval.

Before comparisons between populations, distributions of combined Gm and HLA types were first examined within each control or MS population. Within controls, HLA-A2 was found preferentially in $\mathrm{Gm}^{1} / \mathrm{Gm}^{3}$ heterozygotes (chi-square test, $P$ $=0.018)$ and HLA-B27 in $\mathrm{Gm}^{1} / \mathrm{Gm}^{1}$ homozygotes $(P=0.008)$. Within MS patients, HLA-B7, HLA-DR2, and HLA-B7,DR2 were overrepresented in the $\mathrm{G} 1 \mathrm{~m}(-1)$ subpopulation $(P=0.008$, $P=0.027$, and $P=0.020$, respectively); HLA-A1 was found preferentially in $\mathrm{Gm}^{1} / \mathrm{Gm}^{1}$ patients $(P=0.04)$; and HLA-B35 in $\mathrm{G} 2 \mathrm{~m}(23)$ patients $(P=0.043$, Fisher exact method).

Combined Gm and HLA types and MS susceptibility. Possible MS-related associations of some HLA specificities with given $\mathrm{Gm}$ allotypes or genotypes were investigated by comparison between control and MS populations. $\operatorname{Gm}(1,2,3$ or 23$)$ allotypes were combined with a series of HLA-A, -B, and -DR specificities, whether they displayed a skewed distribution between Gm-related subpopulations in the present study (see above) and/or they were usually MS-associated, namely HLAA1-3, 19; -B5, 7, 8, 12, 14, 18, 27, 35; and -DR1, 2, 3, 7. Most $\mathrm{Gm} / \mathrm{HLA}$ combinations did not exhibit statistically significant differences between MS and controls, including the associations involving HLA-A2 or -B27 as previously found in controls alone, or HLA-A1 or -B7 as found in MS patients. In contrast, differences between populations were observed with two other $\mathrm{Gm} /$ HLA associations first detected in our MS population.

First, within the MS population, the increased frequency of HLA-DR2 was restricted to $\mathrm{G} 1 \mathrm{~m}(-1)$ individuals, a finding that was not observed in controls (Table II, upper portion). G1 m(-1)/ HLA-DR2 individuals are more likely $(P=0.0027)$ to develop MS than any other individuals $(R R=2.59)$. Similarly examining the distribution of HLA-DR2 with respect to individual $\mathrm{Gm}(2$, 3 , or 23) phenotype confirmed the preferential association of HLA-DR2 and G1 $\mathrm{m}(-1)$ in MS. When further dividing the MS and control populations into HLA-B7(+) or (-) subpopulations (Table II, middle and lower portions), this G1 m(-1)/HLA-DR2 association was observed only within HLA-B7(-) patients $(P$ $=0.001)$ but not within HLA-B7 $(+)$ ones $(P=0.43)$; accordingly, RR was above 4 for $\mathrm{Glm}(-1) / \mathrm{HLA}-\mathrm{DR} 2 / \mathrm{B} 7(-)$ individuals whereas it was close to 1 for G1m(-1)/HLA-DR2/B7(+) individuals (Table II).

Second, among the HLA-B35 subjects, none of the MS patients displayed the $\mathrm{G} 2 \mathrm{~m}(-23)$ phenotype, as opposed to controls (Table III); in contrast, among HLA-B35(-) controls and patients, both $\mathrm{G} 2 \mathrm{~m}(23)$ and $\mathrm{G} 2 \mathrm{~m}(-23)$ phenotypes were similarly distributed. Therefore HLA-B35/G2m(-23) individuals are much less likely $(P=0.0015)$ to develop MS than any other individuals $(R R=0.05$, Table III).
Combined Gm and HLA types and MS severity. As detailed elsewhere (14), no $G m$ genotype or phenotype considered alone was associated with high or low values of the $K / D$ severity index. When considering HLA specificities alone, only HLA-B12 was associated with significant variations of $K / D$ ratio $(P<0.03$, Table IV, lower portion). No further influence of other specificities belonging to the $H L A-A 2, B 12, D R 7$ haplotype was evidenced in our MS population.

The selected series of HLA specificities mentioned above was matched with either $\mathrm{Gm}$ allotypes or genotypes. Overall, only HLA-B7/G1m(1) and HLA-B12/G1 m(3) combinations correlated with statistically significant variations of $K / D$.

First, among $G m^{1} / G m^{3}$ heterozygous patients, HLA-B7(+) individuals displayed higher $K / D$ values than HLA-B7(-) ones $(P<0.001)$, irrespective of sex, as shown in Fig. 1. This difference was totally absent in $G \mathrm{~m}^{3} / \mathrm{Gm}^{3}$ patients $(P=0.87)$. It could not be assessed in $\mathrm{Gm}^{1} / \mathrm{Gm}^{1}$ patients, since only one of them was HLA-B7. Finally, it was also observed $(P<0.001)$ when considering all G1m(1) patients (see legend in Fig. 1). When combining HLA-A3 or -DR2 with HLA-B7, no further influence of the former two specificities upon HLA-B7/G1 m(1)-associated variations of $K / D$ was observed. Likewise, among the $\mathrm{G} 1 \mathrm{~m}(1)$ patients, the $\mathrm{G} 1 \mathrm{~m}(2)$ specificity had no influence, despite the existence of a $G m^{1,2 ; 21}$ haplotype.

Second, among $\mathrm{Gm}^{3} / \mathrm{Gm}^{3}$ patients, the HLA-B12 individuals displayed a lower $K / D$ value than the HLA-B12(-) subjects $(P$

Table IV. Influence of HLA-B12 Phenotype and Gm Genotypes on MS Severity Index (K/D)

\begin{tabular}{llll}
\hline Gm genotype & HLA-B12(+) & HLA-B12(-) & \\
\hline$G m^{1} / G m^{1}$ & $0.58 \pm 0.45^{*}$ & $0.57 \pm 0.37$ & NA \\
& $(2)$ & $(7)$ & \\
$G m^{1} / G m^{3}$ & $0.36 \pm 0.31$ & $0.34 \pm 0.23$ & NS \\
& $(7)$ & $(31)$ & \\
$G m^{3} / G m^{3}$ & $0.29 \pm 0.31$ & $0.40 \pm 0.23$ & $P<0.01 \ddagger$ \\
& $(21)$ & $(50)$ & \\
All patients & $0.32 \pm 0.31$ & $0.39 \pm 0.25$ & $P<0.03$ \\
& $(30)$ & $(88)$ &
\end{tabular}

Note that the difference between HLA-B12(+) and $(-)$ patients is still significant $(P<0.02)$ when considering all patients with the $\mathrm{G} 1 \mathrm{~m}(3)$ phenotype, i.e., $G m^{3} / G m^{3}$ and $G m^{1} / G m^{3}$ individuals.

${ }^{*} K / D$ : mean \pm SD and (number of patients).

¥ Mann-Whitney test. NA, not applicable. 


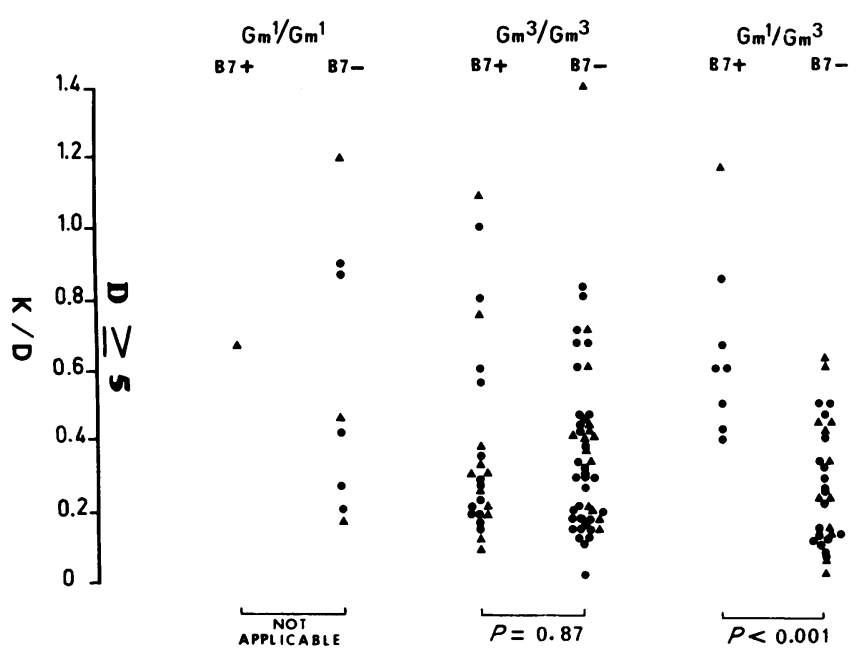

Figure 1. Disease severity expressed as $K / D(D \geqslant 5)$ with respect to patient's $G m$ genotype, HLA-B7 phenotype, and sex ( $\Delta$, male; $\bullet$, female). Statistical comparisons were made with the Mann-Whitney $U$ test. Note that the difference between HLA-B7( +$)$ and $(-)$ individuals is still significant $(P<0.001)$ when considering all patients with the G1m(1) phenotype, i.e., $G m^{1} / G m^{1}$ and $G m^{1} / G m^{3}$ individuals.

$<0.01$ ), whereas this difference was totally lacking in $\mathrm{Gm}^{1} / \mathrm{Gm}^{1}$ and $\mathrm{Gm}^{1} / \mathrm{Gm}^{3}$ patients, as shown in Table IV. This HLA-B12associated variation of $K / D$ was also observed $(P<0.02)$ when considering all patients with a $\mathrm{G} 1 \mathrm{~m}(3)$ phenotype (see legend in Table IV), who together accounted for $92 \%$ of the patients studied. In this G1m(3)/HLA-B12 analysis, no further influences were found when combining HLA-A2 or -DR7 with HLA-B12 on the one hand, or when considering the $\mathrm{G} 2 \mathrm{~m}(23)$ specificity on the other hand.

Given the number of parameters considered, only major results are provided in this section. Complete data are available upon request.

\section{Discussion}

Increased susceptibility to various autoimmune diseases has been shown to simultaneously depend on Gm and HLA phenotypes (23-25). Alleles of both genetic systems could thus be likely candidates for combined influences leading to particular MS susceptibility and/or severity. Matching Gm and HLA specificities generates quite a large number of combinations. Hence, distributions of the latter were first tested within MS or control populations considered separately. In a second step, the distributions of all Gm/HLA combinations that $(a)$ were first found to be unevenly distributed within either population, and $(b)$ involved MS-associated HLA specificities in Caucasians, were compared between populations. The significant results that appeared were further evaluated by taking into account some $\mathrm{Gm}$ genotypes or haplotype-associated HLA specificities, although in some instances this procedure was not applicable since the numbers of individuals within so-delineated subgroups were too small. Sex was also considered, but no general sex-associated pattern could be found (data not shown).

We could demonstrate that the simultaneous presence of HLA-B35 and $\mathrm{G} 2 \mathrm{~m}(-23)$ phenotypes in an individual provides protection against MS. A weak increase or decrease of HLA-
B35 antigen frequency has been reported in MS (7), but, in our study, HLA-B35 alone was not MS-associated (right part of Table III). In the same populations, $\mathrm{Gm}$ phenotypes considered alone have no influence upon MS susceptibility (14). Thus, the present finding dramatically demonstrates the combined effects of both $G m$ and $H L A$ alleles in influencing MS protection. It can be speculated that the $H L A-B 35$ and $G^{-23}$ alleles (the latter encoding some IgG2 heavy chains) together raise an immune response that $(a)$ is particularly adapted to the control of an MScausative agent, or $(b)$ is inefficient against the still elusive MS autoantigen(s). On the other hand, a preferential association of HLA-DR2 with HLA-B7(-) and/or G1m(-1) specificities was found in MS, i.e., the HLA-DR2 specificity was $(a)$ overrepresented in HLA-B7(-) but not among HLA-B7(+) patients, and (b) overrepresented in $\mathrm{G} 1 \mathrm{~m}(-1)$ but not among $\mathrm{G} 1 \mathrm{~m}(1)$ patients; this led to a progressive increase in DR2-related RR. RR was 2 in the overall HLA-DR2 population, about 3 in HLA-B7(-) or $\operatorname{Glm}(-1)$ subpopulations, and above 4 in the HLA-B7(-)/ G1 m(-1) subpopulation, whereas HLA-DR2 did not correlate with an increased $R R$ in any other subpopulation (Table II). The classical HLA-DR2/MS association, extensively described in the literature (4-7), is now enlightened by the preferential HLA-DR2/B7(-) and HLA-DR2/G1 m(-1) associations, which indicate that only some HLA-DR2 individuals are particularly MS-susceptible. As HLA-B7(-) individuals, on the one hand, and $\mathrm{G} 1 \mathrm{~m}(-1)$ individuals, on the other hand, are quantitatively major subpopulations in Caucasians (78\% and $52 \%$, respectively, in our DR-typed control population), this could explain why HLA-DR2/MS associations were commonly found in former studies in Caucasians, although HLA-B7 or Gm specificities were not simultaneously considered. Finally, that both $G m$ and $H L A$ alleles together influence RR for MS could explain why we previously failed to observe in France any $\mathrm{Gm}$-associated increase of RR in MS (14) as opposed to Gm/MS associations found in other countries (9-11).

MS severity was examined using the $K / D$ index, selected among various classifications of severity because it allowed rank test comparisons between values; this avoided qualitative analyses based upon occasionally disputable criteria that implied additional splitting of Gm/HLA-classified subpopulations, as already discussed (14). The HLA-B12 individuals suffered a milder disease than did HLA-B12(-) individuals, a feature that is reminiscent of the previously reported protective influence of HLA-B12 in MS (7). Although this HLA-B12-dependent severity could also be observed among $\mathrm{Glm}(3)$ patients as a whole, we cannot exclude that the $H L A-B 12$ allele acted alone, its role becoming visible within $\mathrm{G} 1 \mathrm{~m}(3)$ patients because they represented $92 \%$ of our MS population. However, this HLA-B12/ severity relationship was clearly marked among $G^{3} / G m^{3}$ patients only (Table IV), a feature that strongly argues for a genuine influence of both $H L A-B 12$ and $\mathrm{Gm}^{3}$ alleles upon MS severity. Such a combined influence of $\mathrm{Gm}$ and $H L A$ alleles was best demonstrated when considering $G m^{1}$ and $H L A-B 7$ (Fig. 1). In the $G m^{1} / G m^{3}$ heterozygous subpopulation, strong differences in $K / D$ ratio related to the HLA-B7 (+ or -) phenotype, whereas within $\mathrm{Gm}^{3} / \mathrm{Gm}^{3}$ homozygotes, the $K / D$ ratio was independent of HLA-B7. As MS severity could not be related to HLA-B7 alone (see Results) nor to any $G m$ allele (14), this clearly indicates that both $G m^{1}$ and $H L A-B 7$ alleles are of importance in severity but only when simultaneously present. Alternatively, this $\mathrm{Gm} /$ HLA-B7 influence observed in G1m(1) patients could exist in 
$G m^{1} / G m^{3}$ subjects only, because of their heterozygous condition at $G m$ loci, a feature whose importance has been demonstrated in other pathological conditions (26).

It has long been considered that the apparent involvement of $H L A-B 7$ allele in $\mathrm{MS}$, as commonly observed, was only related to its linkage disequilibrium with $H L A-D R 2$ within the $H L A$ $A 3, B 7, D R 2$ haplotype $(5,27)$. But, we now demonstrate that, regardless of $H L A-D R 2, H L A-B 7$ has, per se, a strong influence upon MS severity, provided $G m$ loci are simultaneously considered. These results suggest a genuine involvement of alleles in MS at both series of class II and class I antigen-encoding $M H C$ loci. The $G m$-encoded IgGs are exclusively synthesized by B cells that also express MHC class I and II antigens. These three series of molecules play a key role in the end result of regulatory interactions between $B$ and $T$ cells, resulting in antigen presentation-recognition and further suppression or help of the immune response. In this respect, the importance of Gm/HLA associations in the level of physiological immune responses has been shown $(25,28)$. Therefore, and given the facts that in MS (a) a protracted dysregulation of the immune response appears to play a central role (29), (b) a primary B cell abnormality may be involved (30-32), and (c) variations of intrathecal IgG1 synthesis are also Gm/HLA-DR-dependent (33), our present observations argue against $G m$ or $M H C$ alleles being involved only by linkage disequilibrium with alleles at putative MS susceptibility loci, as commonly suggested $(1,7,12,34)$. Instead, interactions between products of given $G m$ and $H L A$ alleles would be, at least partly, responsible for immune abnormalities in this disease.

In studies dealing with the genetic determinants involved in MS, the current concept of susceptibility relies upon those individuals who clinically express the disease. However, silent MS exists (35-36). Despite this present limitation in the appraisal of MS susceptibility, the importance of combined $\mathrm{Gm}$ and $H L A$ alleles, as now described in a French population in which either genetic system considered alone has a weak $(H L A)$ or null $(G m)$ influence, sheds new lights upon susceptibility to or protection against MS. Of further value and possibly of higher clinical relevance is our present finding that some HLA and Gm antigens, when coexpressed in a patient, are associated with a more rapidly crippling MS. In a disease where prognostic indices are lacking, such a combined genetic typing may prove of major usefulness in identifying those patients who should receive new therapies with an optimal risk-to-benefit ratio.

\section{Acknowledgments}

We are indebted to Dr. L. Rivat-Péran and Dr. M. Dujardin for providing us with data related to healthy individuals and MS patients, respectively. Mrs. M. Dutheil and Mrs. A. Chaube are gratefully acknowledged for technical and editorial assistance.

This work was supported in part by grants from Institut National de la Santé et de la Recherche Médicale (CRL No. 82-6014) and the French "Association pour la Recherche sur la Sclérose en Plaques".

\section{References}

1. Haile, R. W., S. E. Hodge, and L. Iselius. 1983. Genetic susceptibility to multiple sclerosis: a review. Int. J. Epidemiol. 12:8-16.

2. Bertrams, J., E. Kuwert, and U. Liedtke. 1972. HL-A antigen and multiple sclerosis. Tissue Antigens. 2:405-408.

3. Jersild, C., A. Svejgaard, and T. Fog. 1972. HL-A antigens associated with multiple sclerosis. Lancet. i:1242-1243.
4. Cohen, D., O. Cohen, A. Marcadet, C. Massart, M. Lathrop, I. Deschamps, J. Hors, E. Schuller, and J. Dausset. 1984. Class II HLADC $\beta$-chain DNA restriction fragments differentiate among $H L A-D R 2$ individuals in insulin-dependent diabetes and multiple sclerosis. Proc. Natl. Acad. Sci. USA. 81:1774-1778.

5. Jersild, C., T. Fog, S. Hansen, M. Thomsen, A. Svejgaard, and B. Dupont. 1973. Histocompatibility determinants in multiple sclerosis with special reference to clinical course. Lancet. ii:1221-1224.

6. McFarlin, D. E., and H. F. McFarland. 1982. Multiple sclerosis (first of two parts). N. Engl. J. Med. 307:1183-1188.

7. Oger, J. J. F., and B. G. W. Arnason. 1984. Immunogenetics of multiple sclerosis. In Immunogenetics. G. S. Panayi and C. S. David, editors. Butterworth Publishers Ltd., London. 177-206.

8. Stendhal-Brodin, L., H. Link, E. Moller, and E. Norrby. 1979. Genetic basis of multiple sclerosis: HLA antigens, disease progression, and oligoclonal IgG in CSF. Acta Neurol. Scand. 59:297-308.

9. Pandey, J. P., J. M. Goust, J. P. Salier, and H. H. Fudenberg. 1981. Immunoglobulin $\mathrm{G}$ heavy chain $(\mathrm{Gm})$ allotypes in multiple sclerosis. J. Clin. Invest. 67:1797-1800.

10. Propert, D. N., C. C. A. Bernard, and M. J. Simons. 1982. Gm allotypes and multiple sclerosis. J. Immunogenet. (Oxf.). 9:359-361.

11. Sandberg-Wollheim, M., L. G. Baird, M. S. Schanfield, M. H. Knoppers, K. Youker, and T. G. Tachovsky. 1984. Association of CSF IgG concentration and immunoglobulin allotype in multiple sclerosis and optic neuritis. Clin. Immunol. Immunopathol. 31:212-221.

12. Ho, H. Z., J. L. Tiwari, R. W. Haile, P. I. Terasaki, and N. E. Morton. 1982. HLA-linked and unlinked determinants of multiple sclerosis. Immunogenetics. 15:509-5i7.

13. Schumacher, G. A., G. Beebe, R. F. Kibler, L. T. Kurland, J. F. Kurtzke, F. McDowell, B. Nagler, W. A. Sibley, W. W. Tourtellotte, and T. A. Williams. 1965. Problems of experimental trials of therapy in multiple sclerosis: report by the panel on the evaluation of experimental trials of therapy in multiple sclerosis. Ann. NY Acad. Sci. 122:552-568.

14. Sesboüé, R., M. Daveau, J. D. Degos, C. Martin-Mondière, J. M. Goust, E. Schuller, L. Rivat-Peran, A. Coquerel, M. Dujardin, and J. P. Salier. 1985. IgG (Gm) allotypes and multiple sclerosis in a French population: phenotype distribution and quantitative abnormalities in CSF with respect to sex, disease severity and presence of intrathecal antibodies. Clin. Immunol. Immunopathol. 37:143-153.

15. Kurtzke, J. F. 1970. Neurologic impairment in multiple sclerosis and the disability status scale. Acta Neurol. Scand. 46:493-512.

16. Ropartz, C., and L. Rivat. 1967. Détermination des groupes Gm, Inv et ISf. Détection des antiglobulines. Spécificité des anti-Rh. In Immunology Techniques. Unit of Immunology, World Health Organization. 32.

17. Steinberg, A. G., and C. E. Cook. 1981. The distribution of human immunoglobulin allotypes. Oxford University Press, Oxford. 1-247.

18. Mittal, K. K., M. R. Mickey, D. P. Singal, and P. I. Terasaki. 1968. Refinement of microdroplet lymphocyte cytotoxicity test. Transplantation (Baltimore). 6:913-927.

19. Legrand, L., and J. Dausset. 1975. A second lymphocyte system (Ly-Li). In Histocompatibility Testing. F. Kissmeyer-Nielsen, editor. Munksgaard/Denmark, Copenhagen. 665-671.

20. World Health Organization. 1984. Nomenclature for factors of the HLA system. Tissue Antigens. 24:73-80.

21. Svejgaard, A., C. Jersild, L. Staub Nielsen, and W. F. Bodmer. 1974. HLA-antigens and disease. Statistical and genetical considerations. Tissue Antigens. 4:95-105.

22. Baur, M. P., M. Neugebauer, and E. D. Albert. 1984. Tables of two locus haplotype frequencies of all MHC markers loci. In Histocompatibility Testing. E. D. Albert, and W. Mayr, editors. Springer Verlag, Berlin. 677-775.

23. Uno, H., T. Sasazuki, H. Tamai, and H. Matsumoto. 1981. Two major genes linked to HLA and Gm control susceptibility to Graves' disease. Nature (Lond.). 292:768-770.

24. Smith, C. I. E., R. Grubb, L. Hammarstrom, and G. Matell. 
1983. Gm allotypes in Swedish myasthenia gravis patients. J. Immunogenet. (Oxf.). 10:1-9.

25. Whittingham, S., I. R. Mackay, and J. D. Mathews. 1984. HLAGm interactions: clinical implications. Clin. Immunol. Allerg. 4:623640.

26. Pandey, J. P., B. T. Shannon, K. Y. Tsang, H. H. Fudenberg, and J. G. Camblin. 1982. Heterozygosity at $\mathrm{Gm}$ loci associated with humoral immunity to osteosarcoma. J. Exp. Med. 155:1228-1232.

27. Degos, L., and J. Dausset. 1974. Histocompatibility determinants in multiple sclerosis. Lancet. i:307-308.

28. Legrand, L., L. Rivat-Peran, C. Huttin, and J. Dausset. 1982. HLA- and Gm-linked genes affecting the degradation rate of antigens (sheep red blood cells) endocytized by macrophages. Hum. Immunol. 4: 1-13.

29. Waksman, B. H., and W. E. Reynolds. 1984. Multiple sclerosis as a disease of immune regulation. Proc. Soc. Exp. Biol. Med. 175:282294.

30. Goust, J. M., E. L. Hogan, and P. Arnaud. 1982. Abnormal regulation of IgG production in multiple sclerosis. Neurology. 32:228234.

31. Goust, J. M., P. M. Hoffman, J. Pryjma, E. L. Hogan, and H. H. Fudenberg. 1980. Defective immunoregulation in multiple sclerosis. Ann. Neurol. 8:526-533.

32. Roos, R. P. 1985. B-cell abnormalities in multiple sclerosis. A hypothesis. Arch. Neurol. 42:73-75.

33. Salier, J. P., C. Martin-Mondière, R. Sesboüé, M. Daveau, J. M. Goust, A. Govaerts, E. Schuller, and J. D. Degos. 1985. HLA-DRdependent variation of intrathecal $\mathrm{IgGl}(\mathrm{Gm})$ allotype synthesis in multiple sclerosis. J. Immunol. 134:1551-1554.

34. Haile, R. W. C., A. Goldstein, L. Field, and M. L. Marazita. 1985. A linkage analysis of the $\mathrm{Gm}$ locus and multiple sclerosis. Genet. Epidemiol. 2:29-34.

35. Herndon, R. M., and R. A. Rudick. 1983. Multiple sclerosis. The spectrum of severity. Arch. Neurol. 40:531-532.

36. Xu, X., and D. E. McFarlin. 1984. Oligoclonal bands in CSF: twins with MS. Neurology. 34:769-774. 